\title{
Asset Building and Child Development: A Policy Model for Inclusive Child Development Accounts
}

\author{
JIN HUANG, MICHAEL SHERRADEN, MARGARET M. CLANCY, \\ SONDRA G. BEVERLY, TRINA R. SHANKS, AND YOUNGMI KIM
}

Extreme wealth inequality imposes significant constraints on financially vulnerable families, especially on the development of children in those families. Child Development Accounts (CDAs)-investment accounts offering financial access, subsidies, and incentives to provide assets for children-are designed to reduce wealth inequality over time and promote human development. We review existing evidence from a test of a CDA policy in a population sample. Findings show that, in addition to stimulating account holding and asset building, universal and automatic CDAs for postsecondary education have positive effects on outlooks for and behaviors of parents and children. This long-running CDA experiment suggests ten design elements for a universal, progressive, and potentially lifelong CDA policy. Informed by findings from this experiment, seven states have adopted some version of this model. These innovations illustrate potential policy pathways to reducing asset inequality and improving child development.

Keywords: asset building, child development, Child Development Accounts, CDAs, policy, wealth inequality

Wealth inequality has become extreme in the United States in recent decades (Saez 2019; Zucman 2019), especially for households with children (Pfeffer and Waitkus 2021, this issue). Relatedly, some scholarship indicates that household wealth has serious implications for child well-being (Beverly, Elliott, and Sherraden
2013; Boen, Keister, and Graetz 2021, this issue; Gibson-Davis and Hill 2021, this issue; Elliott, Destin, and Friedline 2011; Grinstein-Weiss, Shanks, and Beverly 2014; Lerman and McKernan 2008; Miller et al. 2021, this issue; Shanks et al. 2010). This article examines a policy intervention that tests the use of Child Development

Jin Huang is professor in the Saint Louis University School of Social Work, United States. Michael Sherraden is George Warren Brown Distinguished University Professor at the Brown School at Washington University, United States. Margaret M. Clancy is policy director and director of the SEED for Oklahoma Kids experiment at Washington University, United States. Sondra G. Beverly is senior scholar in the Center for Social Development at Washington University, United States. Trina R. Shanks is Harold R. Johnson Collegiate Professor of Social Work and Director of Community Engagement at the University of Michigan, United States. Youngmi Kim is associate professor in the School of Social Work at Virginia Commonwealth University, United States.

(C) 2021 Russell Sage Foundation. Huang, Jin, Michael Sherraden, Margaret M. Clancy, Sondra G. Beverly, Trina R. Shanks, and Youngmi Kim. 2021. "Asset Building and Child Development: A Policy Model for Inclusive Child Development Accounts." RSF: The Russell Sage Foundation Journal of the Social Sciences 7(3): 176-95. DOI: 10.7758/RSF.2021.7.3.08. Direct correspondence to: Jin Huang at jin.huang@slu.edu, 3550 Lindell Blvd., Tegeler Hall 309, St. Louis, MO 63103, United States.

Open Access Policy: RSF: The Russell Sage Foundation Journal of the Social Sciences is an open access journal. This article is published under a Creative Commons Attribution-NonCommercial-NoDerivs 3.0 Unported License. 
Accounts (CDAs) to reduce wealth inequality, support child development, and encourage eventual educational attainment. Opened at birth, CDAs are investment accounts offering financial access and participation, a structured asset accumulation platform, and subsidies for postsecondary education.

Numerous policies implicitly recognize the ways in which household economic resources shape child development. Among those supporting low-income families with children are Temporary Assistance for Needy Families, the Earned Income Tax Credit (Michelmore and Lopoo 2021, this issue), school meals, Head Start, Medicaid (Jackson, Agbai, and Rauscher 2021, this issue), the Children's Health Insurance Program, and child support (Nepomnyaschy et al. 2021, this issue). CDAs are one of the few policy initiatives that specifically address the linkages between household assets and child development (Sherraden 1991). Policy interest in CDAs is growing (U.S. Government Accountability Office 2020; Schuetz 2020). In the United States, seven states have established statewide policies (U.S. Government Accountability Office 2020; Sherraden, Huang, and Zou 2019). CDA programs and policies have also been implemented in Canada, Israel, Korea, Singapore, Uganda, mainland China, Taiwan, and the United Kingdom (Huang, Zou, and Sherraden 2020).

CDAs are grounded in the theory that accumulating household assets can help children eventually pay for postsecondary education expenses. The theory also holds that assets may shape the attitudes and behaviors of parents and children, including their interactions, in ways that promote positive educational outcomes (Sherraden 1991; see also Beverly, Elliott, and Sherraden 2013; Grinstein-Weiss, Shanks, and Beverly 2014; Shanks et al. 2010). For example, having assets for children's postsecondary education may increase parents' educational expectations for the children (Kim et al. 2015), promote their own mental health (Huang, Sherraden, and Purnell 2014), and improve both parenting practices and other parent-child interactions (Huang, Nam, et al. 2019). These attitudes and behaviors contribute to healthy child development. They and the financial assets designated for postsecondary education may help children develop a collegebound identity (Beverly, Elliott, and Sherraden 2013), which can lead in turn to better academic performance and educational attainment. These factors may be especially powerful for disadvantaged families that would not otherwise be able to consider higher education.

In the sections that follow, we first describe the CDA policy concept and its recent development in the United States. We then summarize existing findings on the impacts of universal and automatic CDAs on families' asset building, parental attitudes and behaviors, and child development. We focus on the Saving for Education, Entrepreneurship, and Downpayment program in Oklahoma (SEED OK) CDA program, which was tested in a randomized experiment in a full statewide population with a stratified random sample of families with newborns. We use the SEED OK experiment as an example because it shows how universal and progressive CDA policy could be designed, implemented, and sustained to serve large populations. With insights gained from SEED OK research, we recommend policy design features and discuss their implementation in statewide policies. The goal is to provide a comprehensive summary of CDA impacts and features that can serve as a general guide for future design and implementation.

\section{THE CDA POLICY CONCEPT}

CDAs are viewed as the centerpiece of a universal, progressive, and potentially lifelong policy that offers families a structure within which to accumulate assets over time (Sherraden 1991; Sherraden and Clancy 2005). Universality means providing a CDA to every newborn, and progressivity means allocating extra subsidies and incentives for children from vulnerable families. This inclusive approach enables all children to participate in asset building (powell 2009). As proposed, CDAs are an asset-building framework for the entire life course.

Both the CDA model and subsequently implemented policies encourage families to contribute to the accounts, which also grow from deposits by public, nonprofit, or private sources, as well as from investment earnings. Subsidies and incentives can come in the form of opening deposits, contributions at milestones in the 
beneficiary's life (such as birthdays), savings matches, and tax benefits. Although CDAs were conceived as a tool for accumulating assets for a variety of uses, most related policies in the United States today designate the assets for postsecondary education. CDAs in some other countries-Israel, Taiwan, and United Kingdom, for example-do not restrict assets after children reach certain age milestones.

In the United States, the first coordinated test of CDAs piloted them in twelve communitybased programs between 2003 and 2008 (Sherraden and Stevens 2010). This effort, the Saving for Education, Entrepreneurship, and Downpayment Initiative (SEED National Initiative), recruited 1,171 low-income children and their families in communities in twelve states. ${ }^{1}$ The largest share of SEED participants $(\mathrm{N}=790)$ was affiliated with a program in Pontiac, Michigan, which was also the site for MI-SEED, a quasiexperimental program that offered CDAs to children enrolled at Head Start centers in and around the city (Adams 2008; Loke, Clancy, and Zager 2009). The counterfactual was created by randomly assigning matched pairs of Head Start centers to treatment and comparison groups. The intervention consisted of an account with Michigan's 529 College Savings Plan (MI 529), initial deposits from the program and the state, and opportunities for savings matches. To take up the offer, a treatment family opened an account with the MI 529, after which the initiative contributed $\$ 800$ and the state $\$ 200$. For four years, deposits made by family members into these accounts received a one-to-one match from SEED. After intensive recruitment efforts, 235 (62 percent) of the 381 caregivers in the treatment group opened accounts (Blumenthal and Shanks 2019; Shanks, Johnson, and Nicoll 2008; Shanks, Nicoll, and Johnson 2014); however, the most disadvantaged families in this already low-income sample were the least likely to open accounts.

In December 2008, after the formal program had ended, the CDAs of MI-SEED participants had a mean balance of $\$ 1,483$ and a median value of \$1,131 (Loke, Clancy, and Zager 2009). The MI-SEED sample consisted of children from low-income families who experienced the Great Recession, yet a large majority did not make nonqualified withdrawals and still had positive balances by 2019. As of September 2019, the mean balance was $\$ 1,945$, and the median was $\$ 1,411$. By 2019 , when most of the MI-SEED students were old enough to have graduated from high school, participants began to use their accounts to make qualified withdrawals. Twenty-four individuals made twenty-nine qualified withdrawals, a mean withdrawal of \$1,379 (median \$1,081). Forty-two individuals made forty-seven nonqualified withdrawals, a mean of $\$ 1,313$ (median $\$ 1,000$ ). Analyses with standardized test scores from Michigan suggested that having a CDA was associated with increased likelihood of scoring above proficiency on the reading and math sections of the sixth-grade test $(p<.10)$ and the English and writing section of the eleventh-grade test $(p<$ $.05)$. Those results were robust to the inclusion of controls for economic disadvantage and special education.

Although successful in some ways, MI-SEED revealed the limitations of opt-in enrollment. Despite intensive outreach and explanation, and the offer of an $\$ 800$ initial deposit, only 62 percent of families opened CDAs (Shanks, Johnson, and Nicoll 2008; Shanks, Nicoll, and Johnson 2014), and disadvantaged families were overrepresented in the remaining 38 percent-exactly the opposite of what might be considered most desirable in terms of inclusion. Moreover, 73 percent of parents who did open accounts chose the most conservative guaranteed-income option, which greatly limited investment growth. For example, the average balance of a conservative account in 2019 was $\$ 1,588$ (median of $\$ 1,409$ ), but $\$ 4,228$ (median of $\$ 2,330)$ for more aggressive accounts that included exposure to equities. This experience with the CDA policy model in MI-SEED-

1. The SEED National Initiative was a policy, practice, and research effort led by seven national partners: the Corporation for Enterprise Development (CFED, now known as Prosperity Now), the Center for Social Development (CSD) at Washington University in St. Louis, the University of Kansas School of Social Welfare, the University of Michigan, the New America Foundation, the Initiative on Financial Security at the Aspen Institute, and RTI International (Sherraden and Stevens 2010). 
especially the challenges of opt-in enrollment and low-growth investment choices-later led to the CDA policy model for SEED OK (Sherraden and Clancy 2005). This was a key evidence-based transition in CDA policy development.

In 2018, more than seventy CDA policies and programs operated in the United States; nearly half a million children were enrolled beneficiaries (Prosperity Now 2018). Seven states-California, Illinois, Maine, Nebraska, Nevada, Pennsylvania, and Rhode Island-have adopted statewide, automatic, universal CDA policies by legislation or administrative rule (see table 1) (Clancy, Sherraden, and Beverly 2019a). ${ }^{2}$ These programs were influenced by the results from the CDA policy model research - through reports, testimony, and interstate cooperation (Beverly, Clancy, and Sherraden 2016; Clancy 2019; Clancy and Beverly 2017c; Clancy, Sherraden, and Beverly 2019a). The latest four statewide CDA policies, notably, were created by legislation, in effect moving from demonstrations to regularized public policy. Regarding potential growth, estimates from 2018 birth statistics suggest that about eight hundred thousand children will be added into these policies in 2021. Other states are also taking steps to enact CDA policies; for example, legislation to create statewide CDAs was introduced in both houses in Missouri in early 2020, stalled because of the COVID-19 pandemic, and is expected to be a priority in 2021 (Leiker, Clancy, and Sherraden 2020).

As shown in table 1, these state programs vary in their specific features. Maine, which has the oldest statewide CDA policy in the country, automatically enrolls every resident newborn (about twelve thousand annually), depositing a \$500 grant into the state's 529 plan. The grants are funded by a private philanthropy. The policy matches family savings in a state 529 account at a 50 percent rate up to an annual maximum of \$300 (Clancy and Sherraden 2014; Huang et al. 2013). The savings match is deposited automatically regardless of family income and carries no lifetime maximum (Clancy and Sherraden 2014). In 2018, Pennsylvania became the first state to create a universal and automatic CDA policy through legislation, which passed with bipartisan support (Center for Social Development 2018). The Pennsylvania Keystone Scholars program automatically deposits $\$ 100$ into the state 529 plan for each of the approximately 140,000 residents born annually (Clancy, Sherraden, and Beverly 2019a).

\section{SEED OK}

SEED OK, which began in 2007, is an ongoing, longitudinal, multimethod, randomized experiment of a universal CDA in a full statewide population. It was designed to test the impacts of universal and progressive CDAs opened at birth. Children in the treatment group received a CDA that included a state-owned account, an initial deposit, and incentives to encourage deposits from their families. ${ }^{3}$ Children in the control group did not receive this CDA intervention and had no restrictions of any kind. They and their parents were free to open a 529 account, and some of them did. The evaluation of SEED OK was multimethod and rigorous, including random sampling from a state population, oversamples of populations of color, longitudinal survey data, account data electronically transferred from the state 529 plan, and indepth interviews.

\section{Sample and Data}

The sampling frame was the population of Oklahoma infants born in two three-month periods in 2007. Treatment and control group members were randomly selected from birth records provided by the Oklahoma Health Department. The experiment oversampled racial and ethnic minorities-African Americans, American Indians, and Hispanics-because of our interest in the ties between wealth inequality and race. Mothers of 2,704 newborns agreed to participate. This sampling design produced estimates that were generalizable to the full state population of families with newborns.

2. Several cities have also launched CDA policies, among them San Francisco; Saint Louis, Missouri; New York (City of New York 2017); Oakland; and Lansing, Michigan.

3. SEED OK was funded by the Ford Foundation, Charles Stewart Mott Foundation, and Lumina Foundation for Education. 


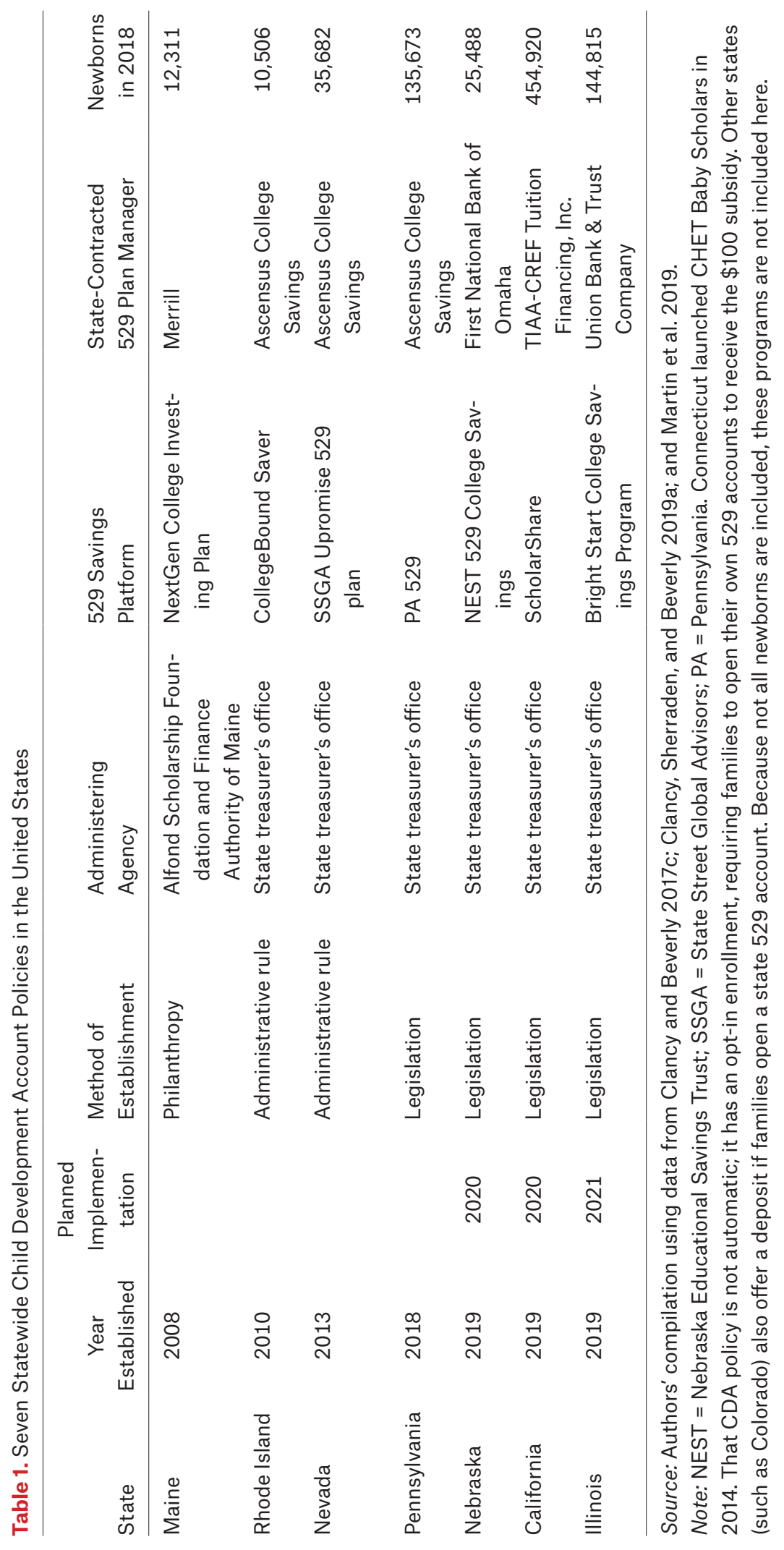


Yunju Nam and colleagues (2013) used demographic data from birth certificates to compare mothers who completed the baseline survey with those who did not. ${ }^{4}$ The two groups did not differ significantly on infant's race and Hispanic origin, gender, and birth weight; mother's marital status and metropolitan residency; and father's age. Participating mothers were slightly older (25.5 versus 25.2 years), slightly more educated (12.5 versus 12.2 years), and slightly more likely to have been born in the United States ( 87 versus 84 percent).

After completing a baseline survey between the fall of 2007 and the spring of 2008, the mothers were randomly assigned to the treatment $(\mathrm{n}=1,358)$ or the control group $(\mathrm{n}=1,346$; Marks, Rhodes, and Scheffler 2008). About 84 percent $(n=2,259)$ completed the wave 2 survey in the spring of 2011, 1,149 in the treatment group and 1,110 in the control group (for descriptive statistics, see Zager et al. 2010). Wave 3 of the survey was conducted in the first half of 2020 .

The evaluation used data from surveys of mothers, account information as provided by the state 529 plan, and in-depth interviews. The Oklahoma 529 College Savings Plan (OK 529) provided quarterly data on ownership of and balances in OK 529 accounts for SEED OK children. Those data were transferred directly to the SEED OK research team from the 529 program manager. Finally, in-depth interviews conducted between mid-2009 and late 2010 provided qualitative data on mothers' experiences with and viewpoints on the CDA (Gray et al. 2012).

\section{SEED OK Intervention}

The SEED OK experiment was built on OK 529's centralized account platform. In general, contributions to 529 accounts are made after tax. Investment earnings are not subject to federal or state taxes if withdrawn for qualified educational expenses at community colleges, trade and vocational schools, four-year colleges, and other postsecondary institutions. However, a 10 percent penalty on investment earnings (as opposed to deposited amounts) is applied to withdrawals for anything other than payment of qualified expenses. Many states, including Oklahoma, offer income tax benefits (whether credits or deductions) for contributions to their 529 plans. In Oklahoma, as elsewhere across the United States, any adult citizen or resident alien may open a 529 account.

SEED OK had an opt-out design. For each child in the treatment group, the Oklahoma treasurer's office automatically opened a stateowned OK 529 account with a $\$ 1,000$ initial deposit. Parents could opt out of the account by contacting the Oklahoma state treasurer's office. (Some CDA policies allow parents to opt out of receiving communications but maintain funds for the child to access when she or he turns eighteen.) Funds in these accounts have been invested in the OK 529 Moderate AgeBased Option (Clancy and Beverly 2017a). ${ }^{5}$ When the beneficiaries are ready to use the funds, withdrawals will be sent directly to postsecondary educational institutions. ${ }^{6}$ Funds that remain in a CDA after the beneficiary turns thirty will revert to the state.

SEED OK also offered two financial incentives designed to encourage treatment mothers to open and make personal deposits into their own OK 529 accounts (mother-owned accounts). At the time, the state plan required a $\$ 100$ deposit to open the account. SEED OK offered the $\$ 100$ initial contribution for accounts opened by a given date. In addition, the experiment provided savings matches for four years (2008-2011) to low- and moderate-income treatment families that made deposits into mother-owned accounts. Families with an annual adjusted gross income under $\$ 29,000$ had a 1 to 1 match rate for their savings (up to $\$ 250$ in matches per year), and those with an annual adjusted gross

4. More than 99 percent of the caregivers completing the baseline survey were mothers of selected newborns. For simplicity, we refer to all caregivers as mothers.

5. Program deposits were initially invested in the OK 529 Balanced Fund Option. Funds were later moved to an age-based option in which investments become increasingly conservative as the beneficiary nears college age.

6. Oklahoma does not count assets in these state-owned accounts or any personal deposits into OK 529 accounts against the asset limits of state means-tested programs (Clancy, Sherraden, and Beverly 2019a). 
Figure 1. Flow Chart of the SEED OK Experiment

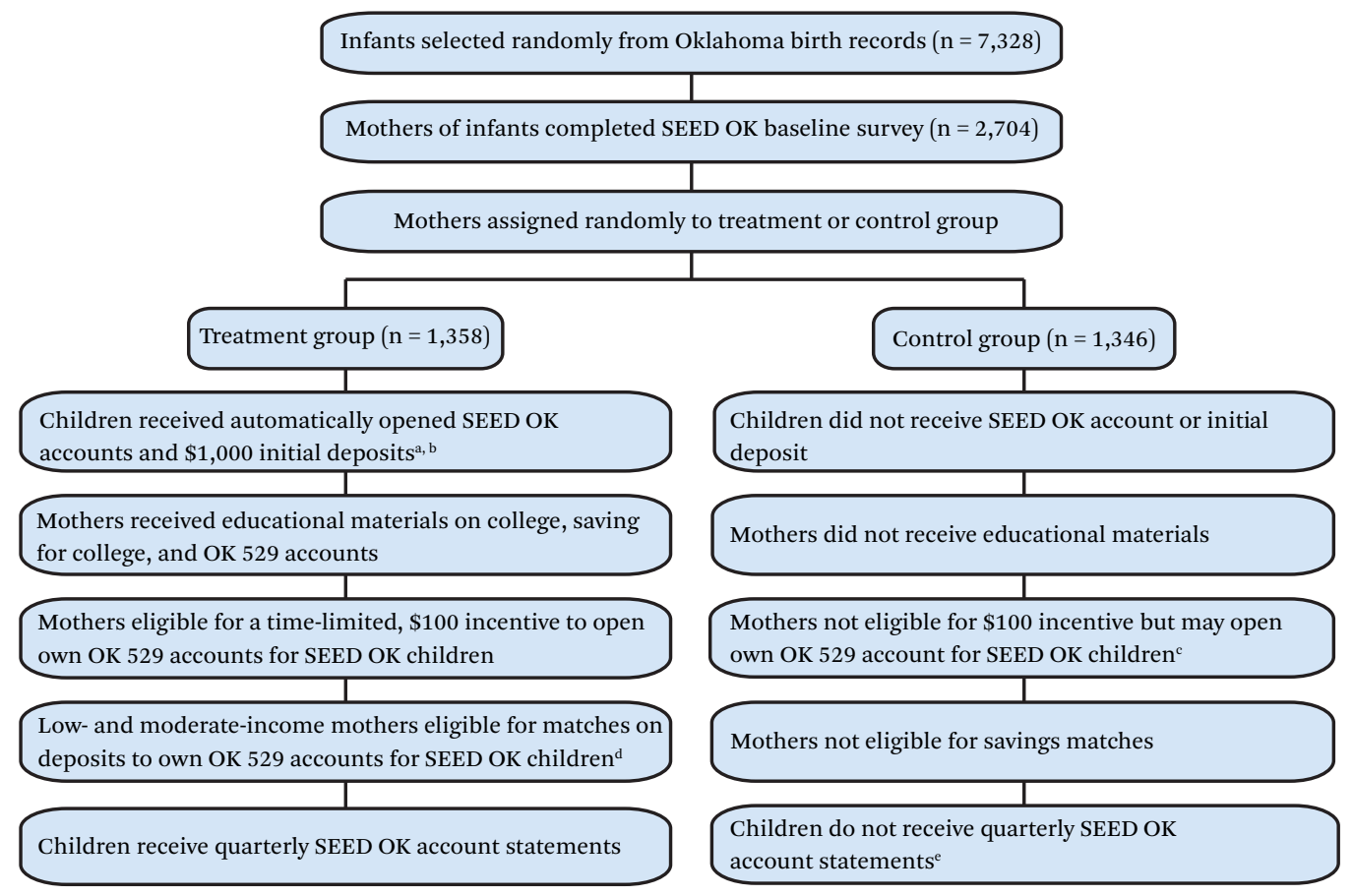

Source: Adapted from Beverly, Clancy, and Sherraden 2016, 2.

Note: SEED OK = SEED for Oklahoma Kids; OK 529 = Oklahoma 529 College Savings Plan.

a One mother opted out of the account for her child for religious reasons.

${ }^{b}$ Funds are restricted for use on qualified postsecondary educational expenses and are sent directly to educational institutions.

${ }^{c}$ Anyone eighteen years or older, regardless of their state residency, can open an OK 529 account.

d Savings matches are held in SEED OK accounts.

e Because they did not receive automatically opened accounts, control children do not receive SEED

OK account statements, but quarterly OK 529 account statements are sent for all mother-owned accounts.

income between $\$ 29,001$ and $\$ 43,499$ received a 0.5 to 1 rate (up to $\$ 125$ in matches per year). Using public-assistance program records and the state tax-return data of consenting participants to assess eligibility, the state automatically deposited savings matches. Families have been able to choose an investment that is more or less aggressive than the state-selected option, withdraw savings easily for personal or financial reasons, and benefit from the state tax deduction.

In each calendar quarter, the OK 529 program manager mailed statements showing the balance of the state-owned account to each treatment family. In addition, SEED OK sent other communication materials (such as letters and postcards), a mailing of two books to be read with children, and a T-shirt reading " $\mathrm{Fu}$ ture College Graduate." SEED OK was a lowresource intervention, did not directly contact treatment mothers, made no professional contact, and did not offer any services. Mothers and other family members in the control group could open OK 529 accounts but did not receive incentives to do so. Figure 1 presents a flow chart for the intervention (Clancy et al. 2016).

\section{Effects on Financial Outcomes}

Published research using SEED OK financial data from 2009, 2010, and 2014 suggested that 
the SEED OK intervention generated positive financial outcomes (Beverly et al. 2015; Clancy et al. 2016; Nam et al. 2013; Sherraden et al. 2015) on account holding and accumulated assets.

SEED OK achieved near universal account holding by automatically opening state-owned accounts. (Very soon after accounts were opened, one mother of a treatment child opted out of the account, citing religious reasons.) The impact of automatic opening was large; in its absence, very few children would have had a 529 account. For example, in 2014, when SEED OK children were about seven years old, fewer than 4 percent in the control group had an OK 529 account (Clancy et al. 2016). Very large and statistically significant treatment-control differences in the percentages of participants holding any OK 529 account were also found in disadvantaged subsamples (Beverly et al. 2012; Clancy et al. 2016; Nam et al. 2013; Sherraden et al. 2015).

Also, the CDA in SEED OK had a large, positive impact on the value of total 529 assets for higher education and a modest one on the value of personal savings held in incentivized 529 individual accounts (Clancy et al. 2016; Nam et al. 2013). On December 31, 2014, the average value of the treatment group's total 529 assets for higher education was $\$ 1,851$, nearly six times that for the control group ( $\$ 323, p<.01)$. The average value of personal savings in individual accounts was greater for treatment children (\$419) than for control children (\$323), but the difference was not statistically significant (Clancy et al. 2016). The average value of total earnings on CDA assets of the treatment group was $\$ 570$, nearly five and a half times that for the control group ( $\$ 109, p<.01)$.

The findings on total 529 assets for higher education were consistent with the incentives and support for savings, including automatic deposits, matching savings, restricting investment options, deferring taxes, and guiding withdrawals. It may be helpful to understand the meaning that accumulated assets can have. Nearly one-third of Americans could not come up with $\$ 2,000$ within a month to meet an unexpected need, and the median net worth of low-income was approximately \$0 (Federal Reserve 2017). In contrast, approximately 18 percent of the experiment's treatment children had assets in individual accounts (Clancy et al. 2016). Was the accumulated amount enough to matter for higher education? If the savings were maintained until they were eighteen years old and the assets earned a 5 percent rate of return, the average balance in individual accounts would be approximately 9 percent of the average total in-state tuition for a four-year postsecondary institution in Oklahoma (Huang et al. 2017). If estimates included the initial $\$ 1,000$ deposit by SEED OK, the $\$ 100$ account-opening deposit, and returns on these deposits, the accumulated sum would cover approximately 13 percent of that tuition (Huang et al. 2017). Other estimates indicated that, on average, parents paid 14 percent of children's postsecondary tuition from savings in 2018 (Sallie Mae and Ipsos 2018).

\section{Effects on Social Development}

The CDAs in SEED OK affected more than asset accumulation. Findings indicated effects on social development outcomes. Using data from the wave 2 survey conducted in 2011, SEED OK research examined the effects of CDAs on parental educational expectations, maternal depressive symptoms, parenting practices, and children's social-emotional development. Asset effects theory guided predictions about the influence of assets on child development and the selection of these outcomes (Grinstein-Weiss, Shanks, and Beverly 2014; Huang, Sherraden, and Purnell 2014; Lerman and McKernan 2008). The theory posited that, because the assets were available, parents would have higher expectations and improve their interactions with children accordingly. Thus, levels of emotional distress and parenting stress would be lower, and the effects would promote child development. Positive parent-child interactions and healthy child development would in turn contribute to positive educational outcomes. However, because children were only four years old at the time of the wave 2 survey, no analyses examined educational outcomes.

The findings suggest that the CDA helped treatment parents sustain high expectations about their children's education (Kim et al. 2015), reduced the intensity of maternal depressive symptoms (Huang, Sherraden, and Purnell 2014), reduced punitive parenting practices 
(Huang, Nam, et al. 2019), and improved children's early social-emotional development (Huang et al. 2014). Details on the measures of these social development outcomes were provided in SEED OK research (Huang et al. 2014; Huang, Nam, et al. 2019; Huang, Beverly, et al. 2019; Huang, Sherraden, and Purnell 2014; Kim et al. 2015). Overall, the effect sizes of CDAs on these outcomes were similar to those of other early childhood interventions such as Early Head Start and Head Start (around 0.10; see Huang, Nam, et al. 2019; Huang, Beverly, et al. 2019; Huang, Sherraden, and Purnell 2014). Some of the magnitudes of effect sizes were larger for the low-income subsample than for the full sample (Huang, Nam, et al. 2019; Huang, Beverly, et al. 2019; Huang, Sherraden, and Purnell 2014). This suggests that universal and automatic CDAs had greater effects on some social development outcomes for lowincome families. In this regard, CDAs have the potential to reduce some child development disparities caused by economic inequality.

Altogether, these outcomes indicate a pattern of modest but meaningful social development improvements that, because of the rigorous research design, can be causally attributed to the CDA. These positive effects were documented even though the CDA funds had not yet been used for education. In other words, assetholding itself made the difference. (We also hypothesize that these assets will later be "spent" and contribute to educational success.)

Findings from extended qualitative interviews conducted with forty SEED OK treatment mothers supported and enriched these quantitative findings on the effects of CDAs. One theme of the interviews was that mothers said the CDA made them feel optimistic about their children's future (Gray et al. 2012). For example, one treatment mother facing great financial pressure stated that the CDA made her feel "a whole lot better" and caused her to "have some hope" for her child (64). Another mother said that the CDA "give[s] me something to look forward to-to know that it would help" (56). For some, the CDA represented a partnership with the state in securing their child's future. The research also indicated that CDAs were more meaningful to mothers with low income and low education than to their more advantaged counterparts.

\section{KEY DESIGN ELEMENTS OF A UNIVERSAL AND PROGRESSIVE CDA POLICY MODEL}

As noted, experimental evidence suggests that CDAs substantially increased the holding of investment accounts and assets for education and had positive impacts on some attitudes and behaviors of children and families. In SEED OK, CDAs also motivated parents of infants to open 529 accounts, though the impact on amount of individual savings was not statistically significant in early childhood. Overall, financial and nonfinancial impacts in CDAs were generated not by individual saving behaviors but by a universal policy model that built opportunities for children and families. We argue that the core feature of successful CDAs is the inclusion of all children, and that the design features of this policy model matter for inclusion and sustainability. Scholars at the Center for Social Development identified ten key elements for universal and progressive CDA policies (Clancy and Beverly 2017c; Clancy, Sherraden, and Beverly 2019a, 2019b; Sherraden, Clancy, and Beverly 2018). These elements are designed to ensure that a policy is universal, progressive, and potentially lifelong, and that it is built on an efficient, scalable, and stable policy model capable of promoting asset accumulation for development purposes.

\section{Universal eligibility}

All children within a jurisdiction are eligible for CDAs under that jurisdiction's policy. For a state or city CDA policy, all children in families across the full socioeconomic and geographic spectrum in the state or city are eligible for the CDA. A national CDA policy will include all children in the country. Ideally, CDAs are not intended to target certain subpopulations such as disadvantaged families. For example, according to California Education Code, each state resident born on or after July 1, 2020, is eligible for a state CDA. ${ }^{7}$ In contrast, the CDAs targeting specific populations (such as clients 
of certain social agencies) risk excluding some disadvantaged children from asset-building opportunities. Some programs target children in public schools but exclude those in religious and private schools, as well as those who are homeschooled. Such exclusions may create barriers for financially vulnerable families given that some religious schools and private schools enroll a substantial proportion of low-income students.

Universal eligibility also avoids the administrative costs associated with eligibility assessment and recruitment and creates a platform to implement automatic enrollment (see next element). The comparison of statewide CDA policies with small-scale community CDA programs with targeted populations suggests that the latter may encounter high administrative and outreach costs, affecting program efficiency and sustainability (Clancy and Sherraden 2014; Huang, Beverly, et al. 2019; Clancy et al. 2019). In addition, the inclusion of moderate- and high-income families through universal eligibility enables cross-subsidization, wherein high balance accounts can help to offset the costs of low-balance accounts, thereby making inclusion of low-balance accounts feasible in the marketplace (Clancy, Orszag, and Sherraden 2004; Clancy, Sherraden, and Beverly 2015; Huang, Beverly, et al. 2019). In sum, full inclusion supports program efficiency, operations, public support, and sustainability. More research should be conducted to quantify the specific benefits of universal eligibility.

\section{Automatic enrollment}

Children are automatically enrolled in the CDA on an opt-out basis. Automatic enrollment removes the burden of voluntary program takeup from parents (Clancy, Sherraden, and Beverly 2019a, 2019b). As research suggests, low take-up among eligible families is a challenge of public benefit programs (Currie 2004). Findings of SEED OK indicate that, with automatic enrollment, it is feasible for CDAs to cover essentially all children (only one family in SEED OK, less than 0.1 percent, has opted out). Compared with a nearly 100 percent participation in automatic SEED OK CDAs, the opt-in MI-SEED CDAs have an enrollment rate of 62 percent following extensive community outreach. The im- portance of universal eligibility with automatic enrollment has also been demonstrated in state CDA policies. The first statewide CDA in the United States, Maine's Harold Alfond College Challenge, originally used an opt-in enrollment approach and invested approximately $\$ 11.5$ million for program outreach to enroll 40 percent of all eligible children between 2008 and 2013. Modeling the SEED OK CDA, the program changed to automatic enrollment in 2014 and now includes all Maine newborns (approximately 12,500 annually), thus saving millions of dollars a year in recruitment costs with almost no additional operational costs (Clancy and Sherraden 2014).

\section{Automatic initial deposit}

All children automatically receive a substantial initial deposit ( $\$ 500$ to $\$ 1,000$ ) when enrolled. Findings from SEED OK strongly support the importance of a sizable initial deposit for asset accumulation: by the end of 2014, about threequarters of accumulated assets in CDAs for treatment children were generated from the initial deposit and its earnings. In addition to individual savings, a substantial initial deposit greatly increases the potential of CDAs to address inequality. Moreover, a substantial initial deposit may be related to CDA effects on parents and children's attitudes and behaviors from the beginning (Beverly, Elliott, and Sherraden 2013). The SEED OK CDA's positive impacts on attitudes and behaviors, even though very few parents have made personal deposits, seem to suggest that the initial deposit designated for postsecondary education brings about these changes. In Pennsylvania, the state government provides a scholarship grant of $\$ 100$ as an initial deposit when automatically enrolling eligible children into the program. More research is required for us to understand better the relationship between the amount of the initial deposit and the effects of the CDA (Beverly, Elliott, and Sherraden 2013).

\section{At-birth start}

State birth records, the only centralized source of such information, enable CDA administrators to enroll beneficiaries when they are born, maximizing the potential for asset growth over time. These records have a second important 
advantage in being the only efficient way to achieve automatic, universal enrollment. For example, Pennsylvania's CDA statute requires the state's Department of Health to transmit infants' birth records for the CDA no later than ninety days after birth. ${ }^{8}$ In the absence of using statewide birth records, a CDA program cannot be truly universal. As we have seen in MI-SEED and other examples, when programs are not universal, they disproportionately leave out the most disadvantaged families, even when the programs are targeted to a low-income population.

\section{Automatic progressive subsidy}

Low-income and disadvantaged children automatically receive additional deposits to boost asset accumulation. SEED OK and assetbuilding policies have shown that low-income families can save but that the amount of household savings may not be enough to achieve particular goals, such as financing postsecondary education. A savings match is a common policy incentive for asset accumulation in CDAs, but it is difficult for low-income families to save for long-term goals and thus to benefit from the match. Therefore, it is highly desirable that other creative and progressive deposits subsidize the asset accumulation of low-income children. Options include a progressive deposit for each year of schooling completed or for each year of service in the community. In 2019, SEED OK offered a progressive deposit to half of the children randomly selected from the treatment group. All of these children received \$200 and low-income children received an additional $\$ 400$ (Clancy, Sherraden, and Beverly 2019c). ${ }^{9}$

\section{Centralized savings plan}

Through a single, central platform, statecontracted organizations manage CDAs and investments. In the United States, state 529 plans have served this function, facilitating statewide partnerships, efficiency, and economies of scale. As an existing financial platform in fortynine states, 529 plans have important features well suited to CDAs, including state sponsorship to enable full inclusion and smooth policy operation, legal and accounting structures to facilitate asset accumulation (such as savings protection, account restrictions, and tax reporting), centralized administration for accounting and recordkeeping functions, and simplified investment opportunities for potential growth. We discuss the detailed benefits of the centralized savings plan built on 529 plans elsewhere (Clancy, Sherraden, and Beverly 2015). In the United States, CDAs that are not built on 529 plans typically use bank accounts, but this choice has several disadvantages (described in Clancy, Sherraden, and Beverly 2015). The value of centralized savings plans in general, and 529 plans in particular, is revealed by the choices made by CDA program and policy designers: all statewide CDAs use 529 plans as the financial platform. By the end of 2019, nearly 90 percent of CDAs were 529 plan accounts (U.S. Government Accountability Office 2020).

\section{Investment growth potential}

To leverage opportunities afforded by longterm market appreciation, CDA deposits are held in funds that have the potential for investment growth over time. Market appreciation can yield substantial assets, especially if deposits are made when the child is very young. As of December 31, 2014, investment earnings account for nearly one-third of the average value of educational assets in the CDAs of SEED OK for the treatment group (Clancy et al. 2016). The initial deposit of $\$ 1,000$ was made into SEED OK CDAs prior to the 2007-2009 financial recession and declined to just below $\$ 700$ during the recession. However, the fund grew to about $\$ 1,900$ by the end of 2019 (Sherraden et al. 2020).

\section{Targeted investment options}

Targeted options streamline the CDA program's investments. One of the most effective ways to simplify program investments and family decision making is to use age-based funds, which are tailored to the beneficiary's age and adjust investment allocations to become more conservative as the beneficiary nears the age for higher education (Clancy and Beverly 2017a). Age-based options simplify fund selection at

8. 72 Pa. Stat. § 312(b)(1) (2019).

9. Effects of the progressive subsidy will be evaluated in SEED OK wave 3 research. 
Table 2. Key Design Elements of a Universal, Progressive CDA Policy Model

\begin{tabular}{|c|c|c|c|c|c|c|}
\hline \multirow[b]{2}{*}{ Design Element } & \multicolumn{6}{|c|}{ Goals of CDA Policy } \\
\hline & $\begin{array}{l}\text { Asset } \\
\text { Building }\end{array}$ & $\begin{array}{c}\text { Child } \\
\text { Development }\end{array}$ & Universality & Progressivity & $\begin{array}{l}\text { Lifelong } \\
\text { Availability }\end{array}$ & $\begin{array}{l}\text { Scalability, } \\
\text { Efficiency, } \\
\text { and Stability }\end{array}$ \\
\hline Universal eligibility & & & s & & & 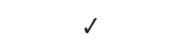 \\
\hline Automatic enrollment & & & $\checkmark$ & & & $\checkmark$ \\
\hline At-birth start & s & s & & & s & $\checkmark$ \\
\hline Automatic initial deposit & s & & a & & & $\mathrm{d}$ \\
\hline Automatic progressive subsidy & $s$ & & & s & & $\checkmark$ \\
\hline Centralized savings plan & $s$ & & s & & & $s$ \\
\hline Investment growth potential & $\checkmark$ & & & & & $s$ \\
\hline Targeted investment options & $s$ & & & & s & $\checkmark$ \\
\hline Restricted withdrawals & $s$ & $\checkmark$ & & & s & $\checkmark$ \\
\hline $\begin{array}{l}\text { Means-tested public benefit } \\
\text { exclusions }\end{array}$ & $s$ & & $\checkmark$ & $\checkmark$ & & $\checkmark$ \\
\hline
\end{tabular}

Source: Authors' compilation.

Note: $\mathrm{CDA}=$ Child Development Account.

enrollment and eliminate pressure to make ongoing investment decisions. They also provide a strategic alternative to fixed interest funds (Clancy and Beverly 2017a). In MI-SEED, the majority of treatment parents who opened MI529 accounts selected the most conservative guaranteed-income option and saw limited investment growth. In statewide CDAs, states typically invest program contributions (such as initial deposits and progressive subsidies) in age-based funds.

\section{Restricted withdrawals}

Assets are restricted to ensure that withdrawn funds are used only for approved purposes. In statewide CDA policies, contributions and earnings from the program may be withdrawn only for postsecondary education expenses. Restricting the use of assets increases the length of investment time, supporting the potential for investment growth. Restricting withdrawals links assets to specific purposes (higher education, for example) and may shape families' attitudes, behaviors, and efforts on these purposes (Clancy, Sherraden, and Beverly 2019a).

10. Means-tested public benefit exclusion Policies protect families' assets and publicassistance benefits by prohibiting public pro- grams from considering CDA funds when determining eligibility for means-tested benefits. Federal legislation already excludes funds in 529 plans from the asset test in the Supplemental Nutrition Assistance Program. Assets in 529 plans are also waived from public benefit eligibility tests in at least eighteen states (Clancy, Sherraden, and Beverly 2015). However, the lack of an exemption of CDA funds from benefitprogram assets tests may negatively affect asset accumulation (Nam 2008; O'Brien 2008; Ratcliffe et al. 2016). Therefore, several states (such as Illinois) hold CDA program deposits in accounts owned by the state because assets in such omnibus accounts do not affect a family's eligibility for public benefits (Clancy, Sherraden, and Beverly 2019a).

In summary, these ten design elements serve the principles of the CDA policy model and, as table 2 illustrates, work together to support the goals of a universal CDA policy. Each element serves multiple policy goals. For example, universal eligibility not only is necessary to achieve inclusive CDA policy but also avoids administrative costs for eligibility review. Automatic initial deposits promote asset building for all families with CDAs. Some design elements rely on others; for example, universal eligibility and 
automatic enrollment are most effectively achieved at birth, when state records can be a central source of information.

Moreover, each of these policy goals is served by multiple elements: universal eligibility, automatic enrollment, at-birth start, and automatic initial deposit create scalable and efficient CDA policy. In addition, centralized savings plans (such as 529s), with investment growth potential and centralized responsibility for accounting, recordkeeping, and investments, are key to establishing efficient, largescale, sustainable, CDA policies that build assets for their beneficiaries.

As table 3 illustrates, the CDA policy tested in SEED OK features all ten design elements. It has become the benchmark model for recent statewide CDA policies. MI-SEED, the quasiexperimental, community-based design component in the SEED National Initiative, features seven of the ten elements. MI-SEED offered the CDA only to children aged three to five at certain Head Start centers in Pontiac, Michigan. In addition, enrollment was not an opt-out process. Families were required to open an MI 529 account to receive the initial deposit and become eligible for the savings match (Shanks, Johnson, and Nicoll 2008; Shanks, Nicoll, and Johnson 2014).

Most statewide CDA policies include nine of the design elements, but none currently includes all ten. The one element notably missing in every statewide policy is an automatic progressive subsidy. State-level budgetary limitations and, in some states, political opposition, constrain current CDA policies from offering additional financial subsidies to low-income and disadvantaged children. Some state treasurers support adding progressive subsidies in the future for all children in the system but, ultimately, a federal government CDA framework that ensures and subsidizes progressivity holds the greatest potential. In this regard, continued expansion of statewide CDAs can set the stage for revisions in the federal 529 framework. The CDA policies of all seven states make an automatic initial deposit, which is a good beginning, but the amounts so far are relatively small, between $\$ 50$ and $\$ 100$. The exception is Maine, which is $\$ 500$ and funded by a philanthropy. These states are building a sustainable structure that may lend itself to something more substantial in the future.

One concern is that personal savings can affect public benefit eligibility. In most states with means-tested public-assistance policies, funds provided by nonpersonal deposits are exempt from the policy's asset limits, and many states waive limits for certain participant programs such as Temporary Assistance for Needy Families. Personal savings may be subject to means tests, but a key design feature of the policy model is the exclusion of CDA deposits from public benefit means tests. As table 3 suggests, a CDA policy is deemed to include this element if the state exempts any funds in the CDAs from an asset test. As Margaret Clancy, Michael Sherraden, and Sondra Beverly note (2019b), assets in 529 plans do not count toward the asset limits for Supplemental Nutrition Assistance Program, the Children's Health Insurance Program, or Medicaid. At least eight states have abolished Temporary Assistance for Needy Families asset limits, and at least fifteen as well as the District of Columbia exclude 529 savings from such limits. State legislation can exempt the 529 plan for purposes of determining eligibility for public assistance, provided that the federal rules for these programs permit such an exemption (Clancy, Sherraden, and Beverly 2019b). Another related policy issue is the effect of personal savings on need-based financial aid for higher education such as Pell Grants, Federal Supplemental Educational Opportunity Grants, and Work-Study assistance. Multiple policy provisions reduce or eliminate the impacts of parental assets on the expected family contribution for students from low- and moderate-income backgrounds. Parental savings and assets therefore typically do not affect need-based aid for dependent students from such families (Clancy and Beverly 2017b).

\section{POLICY IMPLICATIONS AND}

\section{FUTURE DEVELOPMENT}

Increasing wealth inequality raises genuine concerns about its impacts on child development. The challenges of the disparity cannot be resolved solely or even mostly by individuallevel solutions. Substantial structural changes are required; in other words, institutional arrangements and policy strategies must focus 


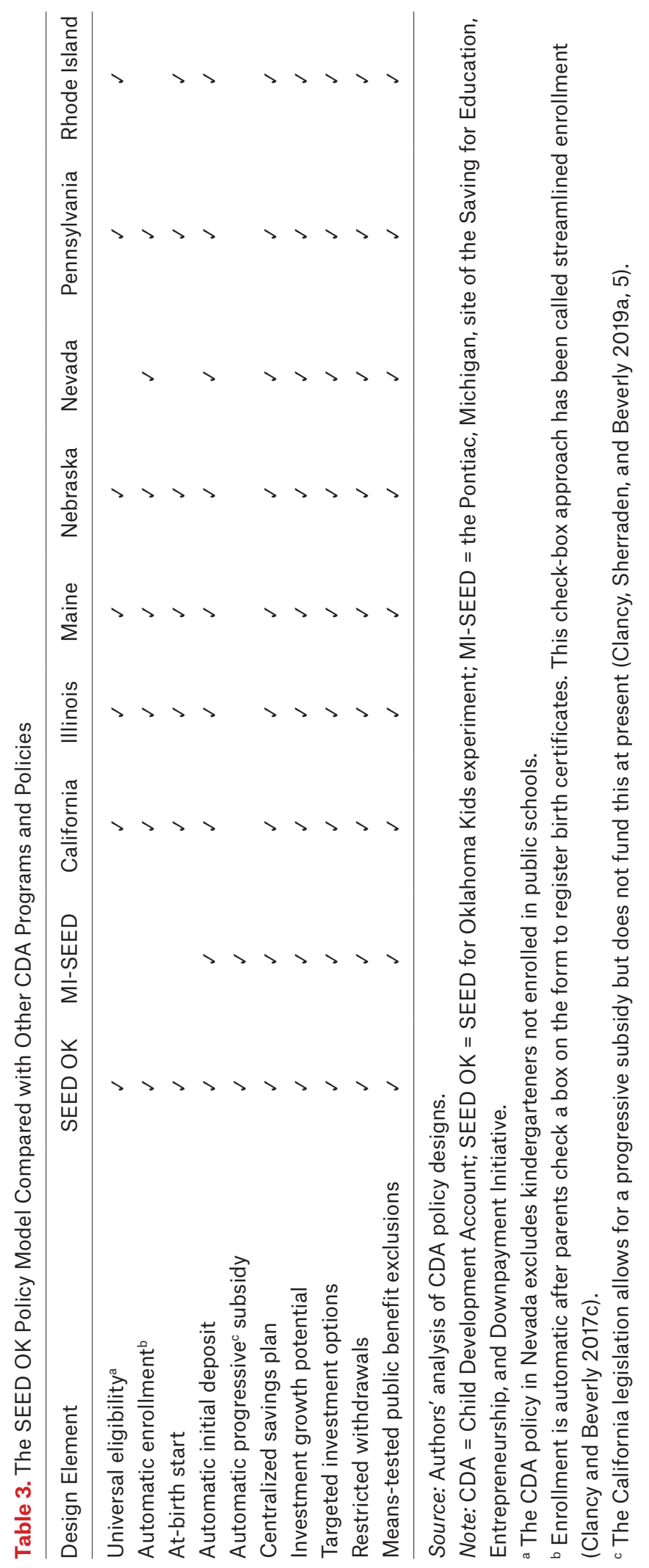


on structural inequalities. CDA policy, as discussed in this article, is designed to build assets and encourage families to save- that is, to invest effectively in children's development. Although it is unrealistic to expect that wealth inequality could be significantly reduced by any single policy or strategy, community-based CDA programs operated by social service organizations have shown some benefits for lowincome and low-wealth families (Sherraden and Stevens 2010). However, when a CDA policy opens accounts automatically, is built on a centralized financial structure capable of including all children, and offers additional progressive subsidies to disadvantaged families, it has the potential to deliver the accounts at scale in a financially sustainable way and to become an institutional tool for helping address disparities in wealth and child development.

State adoption of the universal and automatic CDA model reflects recent efforts toward inclusive policy. To inform the large-scale development of CDA policy at the state and federal levels, it is important to understand whether this policy model affects household wealth accumulation and child development, as well as whether it can reach a large population efficiently and sustainably.

Findings from the SEED OK experiment and other CDA research indicate that CDAs increase families' asset accumulation for child development, improve parents' attitudes toward longterm development and their interactions with children, and promote children's socialemotional development. Given their inclusive and progressive features, CDAs often have greater effects on low-income and low-wealth families than on the population as a whole. These effects in turn suggest the policy's potential to reduce, at least modestly, wealth inequality and child development disparities.

In terms of policy design, SEED OK successfully models automatic enrollment in a centralized savings structure (OK 529), demonstrating that it is feasible to create an inclusive CDA policy platform. After four years of implementation, from 2008 through 2011, no additional interventions, outreach efforts, or administrative activities were undertaken except for minor communication for research sample maintenance. All of the accounting, recordkeeping, and investment activities are managed by the state-contracted 529 plan program manager, such as TIAA-CREF in the case of OK 529. The CDA in SEED OK has operated efficiently since inception. The ten core design elements described in this article support a scalable, efficient, and sustainable policy model (Clancy and Beverly 2017c). We emphasize that, in SEED OK, the state 529 plan clearly demonstrates the capability to serve all Oklahoma children. In other words, an exclusive public policy has been changed to become fully inclusive. Achieving this demonstrated policy transformation is as important as measured CDA impacts on individual children and families because it establishes the potential for sustainable change.

Ideally, more research will be conducted to test other features of CDA policy design. For example, assets in CDAs are restricted to postsecondary education expenses in the United States but in some countries can be withdrawn for other purposes. Different uses of CDA assets may have different impacts on children and their families.

At this writing, seven states have followed the SEED OK example by adopting a similar model, initiating statewide CDA policies to develop their state's workforce (Leiker, Clancy, and Sherraden 2020) and to address the challenge of wealth inequality and child development. Most key design elements are satisfied in their policies. Momentum in state CDA policy development has been increasing over the last several years, informed directly by SEED OK research results. Additional state-level discussions are under way and more related policy development seems likely in the future.

In 2021, more than five hundred thousand newborns will automatically receive a CDA as the continuation of universal policy development. This universal inclusion is an important step. Not only is money invested in the child's name for education and potentially other approved developmental purposes, but lowwealth households and households of color, many of which have had zero or negative net worth, also begin to build an asset worth thousands of dollars. As intended, the universal and automatic CDA in SEED OK eliminates or dramatically reduces disparities by race and ethnicity in ownership of accounts and asset ac- 
cumulation for postsecondary education. Further, the trusted institutional structure of the 529 plan could become a delivery platform for reparations or other targeted remedies and funding for particular groups, which would reflect the full meaning of targeted universalism.

The seven statewide policies are an important foundation for CDA policy expansion in other states and at the federal level. CDAs have been included in several federal legislative proposals, often with bipartisan support. For example, the America Saving for Personal Investment, Retirement, and Education (ASPIRE) Act has been introduced in several sessions of Congress (Cramer 2009; Cramer and Schreur 2015), and the USAccounts: Investing in America's Future Act was introduced in 2015 (Harvin 2016). ${ }^{10}$ Both proposals would open an account and provide an initial deposit for every newborn in the country. Both would provide a progressive savings match. Funds could be used for postsecondary education, homeownership, and retirement security. These provisions are consistent with several design elements listed in the universal CDA policy model. A national policy would have the greatest potential to include all children, reduce disparities in household wealth, and promote child development.

The universal CDA model has also been adopted outside the United States (Sherraden, Huang, and Zou 2019). For example, Singapore initiated comprehensive policies based on four national programs to build assets for all children - the Baby Bonus and Child Development Accounts, Edusave Accounts, Post-Secondary Education Accounts, and Medisave Accounts. In practice, these accounts function as an integrated CDA policy for education and health, a policy linked to the account holder's Central Provident Fund for housing and retirement (Loke and Sherraden 2019). Another example is the Saving for Every Child Program, Israel's newly implemented policy for all children under the age of eighteen (Grinstein-Weiss et al. 2019).

As more children are included in CDA policies, researchers and policymakers wait to learn how the children will fare. Does having a CDA help to improve children's academic per- formance? Does it make them more likely than their peers to graduate from high school and go on to postsecondary education or training? When all children have CDAs, will public funding change to build assets at least equally, if not progressively? Can state 529 plans be remodeled to further reduce regressivity in public funding and better use public resources for asset building for all children? Can CDAs measurably reduce wealth inequality, especially by race? Over the long term, can CDAs transition from a focus on children to become a lifelong asset-building policy? Notwithstanding promising results from the SEED OK experiment and other CDA research, future research should address these and other longer-term questions.

\section{REFERENCES}

Adams, Deborah. 2008. “SEED Preschool Demonstration and Impact Assessment." Lawrence: University of Kansas School of Social Welfare.

Beverly, Sondra G., Margaret M. Clancy, and Michael Sherraden. 2016. "Universal Accounts at Birth: Results from SEED for Oklahoma Kids." CSD research summary 16-07. St. Louis, Mo.: Washington University, Center for Social Development. DOI: 10.7936/K7QC030S.

Beverly, Sondra G., William Elliott III, and Michael Sherraden. 2013. "Child Development Accounts and College Success: Accounts, Assets, Expectations, and Achievements." CSD Perspective 13-27, November. St. Louis, Mo.: Washington University, Center for Social Development. DOI: 10.7936 /K7805247.

Beverly, Sondra G., Youngmi Kim, Michael Sherraden, Yunju Nam, and Margaret M. Clancy. 2012. “Socioeconomic Status and Early Savings Outcomes: Evidence from a Statewide Child Development Account Experiment." CSD research brief 12-34, July. St. Louis, Mo.: Washington University, Center for Social Development. DOI: 10 .7936/K7D21X40.

—. 2015. "Can Child Development Accounts Be Inclusive? Early Evidence from a Statewide Experiment." Children and Youth Services Review 53 (June): 92-104. DOI: 10.1016/j.childyouth .2015.03.003.

Blumenthal, Anne, and Trina R. Shanks. 2019. “Communication Matters: A Long-Term Follow-Up

10. USAccounts: Investing in America's Future Act of 2015, H.R. 4045, 114th Cong. (2015). 
Study of Child Savings Account Program Participation." Children and Youth Services Review 100:136-46. DOI: 10.1016/j.childyouth.2019 .02.016.

Boen, Courtney, Lisa A. Keister, and Nick Graetz. 2021. "Household Wealth and Child Body Mass Index: Patterns and Mechanisms." RSF: The Russell Sage Foundation Journal of the Social Sciences 7(3): 80-100. DOI: 10.7758/RSF.2021 7.3.04.

Center for Social Development. 2018. “Pennsylvania Adopts Universal Child Development Account Policy." Last modified June 27, 2018. https://csd .wustl.edu/pennsylvania-adopts-universal-child -development-account-policy.

City of New York. 2017. “Mayor de Blasio, Commissioner Menin and NYC Kids Rise Announce Queens Public School District to Pilot the First NYC Child Savings Account Program, Helping Thousands of Students Save for College." News release, January 5. Accessed March 16, 2021. https://www1.nyc.gov/office-of-the-mayor /news/008-17/mayor-de-blasio-commissioner -menin-nyc-kids-rise-queens-public-school -district-to.

Clancy, Margaret M. 2019. “The Meadowlark Scholarship Act: Testimony on L.B. 544 before the Education Committee, 106th Nebraska Legislature." CSD testimony 19-03. St. Louis, Mo.: Washington University, Center for Social Development. DOI: 10.7936/683w-bn26.

Clancy, Margaret M., and Sondra G. Beverly. 2017a. “529 Plan Investment Growth and a QuasiDefault Investment for Child Development Accounts." CSD policy brief 17-42, November. St. Louis, Mo.: Washington University, Center for Social Development. DOI: 10.7936/K7F $76 \mathrm{C} 1 \mathrm{Z}$.

_ 2017b. “Do Savings and Assets Reduce NeedBased Aid for Dependent Students?" CSD policy brief 17-10, February. St. Louis, Mo.: Washington University, Center for Social Development. DOI: 10.7936/K7KW5FJX.

_. 2017c. "Statewide Child Development Account Policies: Key Design Elements." CSD research report 17-30. St. Louis, Mo.: Washington University, Center for Social Development. DOI: 10.7936/K7G44PS2.

Clancy, Margaret M., Sondra G. Beverly, Michael Sherraden, and Jin Huang. 2016. “Testing Universal Child Development Accounts: Financial Ef- fects in a Large Social Experiment." Social Service Review 90(4): 683-708. DOI: 10.1086/68 9756.

Clancy, Margaret M., Peter Orszag, and Michael Sherraden. 2004. "College Savings Plans: A Platform for Inclusive Saving Policy?" CSD perspective 04-25. St. Louis, Mo.: Washington University, Center for Social Development. DOI: 10.7936 /K7VQ327B.

Clancy, Margaret M., and Michael Sherraden. 2014. "Automatic Deposits for All at Birth: Maine's Harold Alfond College Challenge." CSD policy report 14-05. St. Louis, Mo.: Washington University, Center for Social Development. DOI: 10.7936 /K7X63MGJ.

Clancy, Margaret M., Michael Sherraden, and Sondra G. Beverly. 2015. “College Savings Plans: A Platform for Inclusive and Progressive Child Development Accounts." CSD policy brief 15-07, January. St. Louis, Mo.: Washington University, Center for Social Development. DOI: 10.7936/K7F18Z8T.

—. 2019a. "Child Development Accounts at Scale: Sample State Legislation." CSD policy summary 19-46. St. Louis, Mo.: Washington University, Center for Social Development. DOI: 10 .7936/cptg-2n77.

_. 2019b. "Essential Policy Design Elements for Statewide Child Development Accounts." CSD fact sheet 19-47, December. St. Louis, Mo.: Washington University, Center for Social Development. DOI: 10.7936/1rvq-dy43.

_. 2019c. "SEED for Oklahoma Kids Wave 3: Extending Rigorous Research and a Successful Policy Model." CSD research brief 19-06, March. St. Louis, Mo.: Washington University, Center for Social Development. DOI: 10.7936/zx2j-0543.

Clancy, Margaret M., Michael Sherraden, Jin Huang, Sondra G. Beverly, and Youngmi Kim. 2019. "Statewide Child Development Accounts and Local Partnerships: A Scalable Model that Can Include All Families." CSD policy brief 19-45, November. St. Louis, MO: Washington University, Center for Social Development. DOI: 10.7936 /q310-7h95.

Cramer, Reid. 2009. "The ASPIRE Act of 2009: Questions and Answers." Washington, D.C.: New America Foundation.

Cramer, Reid, and Elliot Schreur. 2015. “Ensure Every Child Has a Lifelong Savings Account." Paper in the series Pioneering Change: Innovative Ideas for Children and Families. Washington, D.C.: First 
Focus on Children. Accessed March 16, 2021. https://firstfocus.org/wp-content/uploads/2015 /04/Ensure-Every-Child-Has-a-Lifelong-Savings -Account.pdf.

Currie, Janet. 2004. “The Take Up of Social Benefits." NBER working paper no. W10488. Cambridge, Mass.: National Bureau of Economic Research. DOI: 10.3386/w10488

Elliott, William, III, Mesmin Destin, and Terri Friedline. 2011. "Taking Stock of Ten Years of Research on the Relationship Between Assets and Children's Educational Outcomes: Implications for Theory, Policy and Intervention." Children and Youth Services Review 33(11): 2312-28. DOI: 10 .1016/j.childyouth.2011.08.001.

Federal Reserve Bank of New York (Federal Reserve). 2017. "At a Glance: Findings from the February SCE Credit Access Survey." Accessed November 1, 2020. New York: Federal Reserve Bank of New York. https://www.newyorkfed.org/micro economics/sce/credit-access.html\#/.

Gibson-Davis, Christina, and Heather D. Hill. 2021. "Childhood Wealth Inequality in the United States: Implications for Social Stratification and Well-Being." RSF: The Russell Sage Foundation Journal of the Social Sciences 7(3): 1-26. DOI: 10.7758/RSF.2021.7.3.01.

Gray, Karen, Margaret M. Clancy, Michael Sherraden, Kristen Wagner, and Julie Miller-Cribbs. 2012. "Interviews with Mothers of Young Children in the SEED for Oklahoma Kids College Savings Experiment." CSD research report 12-53. St. Louis, Mo.: Washington University, Center for Social Development. DOI: 10.7936/K779445X.

Grinstein-Weiss, Michal, Olga Kondratjeva, Stephen P. Roll, Ofir Pinto, and Daniel Gottlieb. 2019. “The Saving for Every Child Program in Israel: An Overview of a Universal Asset-Building Policy." Asia Pacific Journal of Social Work and Development 29(1): 20-33. DOI: 10.1080/02185385 .2019.1574600.

Grinstein-Weiss, Michal, Trina R. Shanks, and Sondra G. Beverly. 2014. “Family Assets and Child Outcomes: Evidence and Directions." Future of Children 24(1): 147-70. DOI: 10.1353/foc.2014 .0002.

Harvin, Monica. 2016. “Congressmen Seek to Help the $97 \%$ of Families Without a College Savings 529 Plan." GoodCall Education News, May 4.

Huang, Jin, Sondra G. Beverly, Margaret M. Clancy, Terry Lassar, and Michael Sherraden. 2013. “Early
Program Enrollment in a Statewide Child Development Account Program." Journal of Policy Practice 12(1): 62-81. DOI: 10.1080/15588742.2012 .739124 .

Huang, Jin, Sondra G. Beverly, Youngmi Kim, Margaret M. Clancy, and Michael Sherraden. 2019. “Exploring a Model for Integrating Child Development Accounts with Social Services for Vulnerable Families." Journal of Consumer Affairs 53(3): 770-95. DOI: 10.1111/joca.12239.

Huang, Jin, Youngmi Kim, Michael Sherraden, and Margaret M. Clancy. 2017. “Heterogeneous Effects of Child Development Accounts on Savings for Children's Education." Journal of Policy Practice 16(1): 59-80. DOI: 10.1080/15588742 .2015 .1132402 .

Huang, Jin, Yunju Nam, Michael Sherraden, and Margaret M. Clancy. 2019. “Impacts of Child Development Accounts on Parenting Practices: Evidence from a Randomised Statewide Experiment." Asia Pacific Journal of Social Work and Development 29(1): 34-47. DOI: 10.1080/02185 385.2019.1575270.

Huang, Jin, Michael Sherraden, Youngmi Kim, and Margaret M. Clancy. 2014. “Effects of Child Development Accounts on Early Social-Emotional Development: An Experimental Test." JAMA Pediatrics 168(3): 265-71. DOI: 10.1001/jama pediatrics.2013.4643.

Huang, Jin, Michael Sherraden, and Jason Q. Purnell. 2014. "Impacts of Child Development Accounts on Maternal Depressive Symptoms: Evidence from a Randomized Statewide Policy Experiment." Social Science and Medicine 112(1): 3038. DOI: 10.1016/j.socscimed.2014.04.023.

Huang, Jin, Li Zou, and Michael Sherraden, eds. 2020. Inclusive Child Development Accounts: Toward Universality and Progressivity. Abingdon: Routledge.

Jackson, Margot, Chinyere Agbai, and Emily Rauscher. 2021. "The Effects of State-Level Medicaid Coverage on Family Wealth." RSF: The Russell Sage Foundation Journal of the Social Sciences 7(3): 216-34. DOI: 10.7758/RSF.2021.7.3.10.

Kim, Youngmi, Michael Sherraden, Jin Huang, and Margaret M. Clancy. 2015. “Child Development Accounts and Parental Educational Expectations for Young Children: Early Evidence from a Statewide Social Experiment." Social Service Review 89(1): 99-137. DOI:10.1086/680014.

Leiker, Chris, Margaret M. Clancy, and Michael Sher- 
raden. 2020. "Insights from State Treasurers: Developing and Implementing Statewide Child Development Account Policies." CSD policy summary 20-19. St. Louis, Mo.: Washington University, Center for Social Development. DOI: 10 .7936/14tc-2b43.

Lerman, Robert I., and Signe-Mary McKernan. 2008. "Benefits and Consequences of Holding Assets." In Asset Building and Low-Income Families, edited by Signe-Mary McKernan and Michael Sherraden. Washington, D.C.: Urban Institute Press.

Loke, Vernon, Margaret M. Clancy, and Robert Zager. 2009. "Account Monitoring Research at Michigan SEED." CSD Research Report 09-62. St. Louis, Mo.: Washington University, Center for Social Development. DOI: 10.7936/K7FT8KHB.

Loke, Vernon, and Michael Sherraden. 2019. "Building Assets from Birth: Singapore's Policies." Asia Pacific Journal of Social Work and Development 29(1): 6-19. DOI: 10.1080/02185385.2019.1571940

Marks, Ellen L., Bryan B. Rhodes, and Scott Scheffler. 2008. "SEED for Oklahoma Kids: Baseline Analysis." Research Triangle Park, N.C.: RTI International.

Martin, Joyce A., Brady E. Hamilton, Michelle J. K. Osterman, and Anne K. Driscoll. 2019. "Births: Final Data for 2018." National Vital Statistics Reports 68, no. 13. Hyattsville, Md.: National Center for Health Statistics. Accessed December 22, 2020. https://www.cdc.gov/nchs/data/nvsr /nvsr68/nvsr68_13-508.pdf.

Michelmore, Katherine, and Leonard M. Lopoo. 2021. "Exposure to the Earned Income Tax Credit in Early Childhood and Family Wealth." RSF: The Russell Sage Foundation Journal of the Social Sciences 7(3): 196-215. DOI: 10.7758/RSF.2021 7.3.09.

Miller, Portia, Tamara Podvysotska, Laura Betancur, and Elizabeth Votruba-Drzal. 2021. "Wealth and Child Development: Differences in Associations by Family Income and Developmental Stage." RSF: The Russell Sage Foundation Journal of the Social Sciences 7(3): 152-74. DOI: 10.7758/RSF .2021.7.3.07.

Nam, Yunju. 2008. “Welfare Reform and Asset Accumulation: Asset Limit Changes, Financial Assets, and Vehicle Ownership." Social Science Quarterly 89(1): 133-54. DOI: 10.1111/j.1540-6237 .2008.00525.x

Nam, Yunju, Youngmi Kim, Margaret M. Clancy, Robert Zager, and Michael Sherraden. 2013. “Do
Child Development Accounts Promote Account Holding, Saving, and Asset Accumulation for Children's Future? Evidence from a Statewide Randomized Experiment." Journal of Policy Analysis and Management 32(1): 6-33. DOI: 10.1002 /pam.21652.

Nepomnyaschy, Lenna, Allison Dwyer Emory, Kasey J. Eickmeyer, Maureen R. Waller, and Daniel P. Miller. 2021. "Parental Debt and Child WellBeing: What Type of Debt Matters for Child Outcomes?" RSF: The Russell Sage Foundation Journal of the Social Sciences 7(3): 122-51. DOI: 10 .7758/RSF.2021.7.3.06.

O’Brien, Rourke. 2008. “Ineligible to Save? Asset Limits and the Saving Behavior of Welfare Recipients." Journal of Community Practice 16(2): 18399. DOI: 10.1080/10705420801998003.

Pfeffer, Fabian T., and Nora Waitkus. 2021. "Comparing Child Wealth Inequality Across Countries." RSF: The Russell Sage Foundation Journal of the Social Sciences 7(3): 28-49. DOI: 10.7758/RSF .2021.7.3.02.

powell, john a. 2009. "Post-Racialism or Targeted Universalism?" Denver University Law Review 86 (Special Issue): 785-806.

Prosperity Now. 2018. "An In-Depth Look at the CSA Field: State and Local Policy." October. Washington, D.C.: Campaign for Every Kid's Future and Prosperity Now. Accessed December 22, 2020. https://prosperitynow.org/sites/default/files /resources/CSA_Policy_Brief_Field_Scan_0.pdf.

Ratcliffe, Caroline, Signe-Mary McKernan, Laura Wheaton, and Emma Cancian Kalish. 2016. “The Unintended Consequences of SNAP Asset Limits." July. Washington, D.C.: Urban Institute, Opportunity and Ownership Initiative. Accessed December 22, 2020. http://www.urban.org /research/publication/unintended-consequences -snap-asset-limits.

Saez, Emmanuel. 2019. “Striking It Richer: The Evolution of Top Incomes in the United States (Updated with 2017 Final Estimates)." Berkeley: University of California, Department of Economics. Accessed December 22, 2020. https://eml .berkeley.edu/ saez/saez-UStopincomes-2017.pdf.

Sallie Mae and Ipsos. 2018. "How America Saves for College: Sallie Mae's National Study of Parents with Children under Age 18." Newark, Del.: Sallie Mae and Ipsos. Accessed March 16, 2021. https://ww.salliemae.com/assets/about/who _we_are/HAS2018_Full_Report.pdf. 
Schuetz, Jenny. 2020. “Rethinking Homeownership Incentives to Improve Household Financial Security and Shrink the Racial Wealth Gap." Brookings Blueprints for American Renewal \& Prosperity brief, December 9. Washington, D.C.:

Brookings Institution. Accessed December 22, 2020. https://www.brookings.edu/research /rethinking-homeownership-incentives-to -improve-household-financial-security-and-shrink -the-racial-wealth-gap.

Shanks, Trina R., Toni Johnson, and Kerri Nicoll. 2008. "Helping People Act on Their Hopes Rather Than Their Fears: Lessons from NonEnrollees in the SEED Initiative." SEED research report. Lawrence: University of Kansas. DOI: $10.7936 /$ K70 28R2Z.

Shanks, Trina R., Youngmi Kim, Vernon Loke, and Mesmin Destin. 2010. "Assets and Child WellBeing in Developed Countries." Children and Youth Services Review 32(11): 1488-96. DOI: 10.1016/j.childyouth.2010.03.011.

Shanks, Trina R., Kerri Nicoll, and Toni Johnson. 2014. "Assets and African Americans: Attempting to Capitalize on Hopes for Children Through College Savings Accounts." Review of Black Political Economy 41(3): 337-56. DOI: 10.1007/s12 114-014-9185-y.

Sherraden, Michael. 1991. Assets and the Poor: A New American Welfare Policy. Armonk, N.Y.: M. E. Sharpe.

Sherraden, Michael, and Margaret M. Clancy. 2005. "The Universal Model in SEED." St. Louis, Mo.: Washington University, Center for Social Development. DOI: 10.7936/K71R6Q03.

Sherraden, Michael, Margaret M. Clancy, and Sondra G. Beverly. 2018. “Taking Child Development Accounts to Scale: Ten Key Policy Design Elements." CSD policy brief 18-08, February. St. Louis, Mo.: Washington University, Center for Social Development. DOI: 10.7936/K71C1WF9.

Sherraden, Michael, Margaret M. Clancy, Jin Huang, and Sondra G. Beverly. 2020. “Child Development Accounts in the COVID-19 Crisis: Lessons from the Great Recession." CSD research and policy report 20-11. St. Louis, Mo.: Washington University, Center for Social Development. DOI: 10.7936/c5dg-qz60.

Sherraden, Michael, Margaret M. Clancy, Yunju Nam, Jin Huang, Youngmi Kim, Sondra G. Beverly, Lisa Reyes Mason, et al. 2015. "Universal Accounts at Birth: Building Knowledge to Inform Policy." Journal of the Society for Social Work and Research 6(4): 541-64. DOI: 10.1086/684139.

Sherraden, Michael, Jin Huang, and Li Zou. 2019. “Toward Universal, Progressive, and Lifelong Asset Building: Introduction to the Special Issue on Inclusive Child Development Accounts." Asia Pacific Journal of Social Work and Development 29(1): 1-5. DOI: 10.1080/02185385.2019.157 5272.

Sherraden, Michael, and Julia Stevens. 2010. “Lessons from SEED, a National Demonstration of Child Development Accounts." CSD Research Report 10-35. St. Louis, Mo.: Washington University, Center for Social Development. DOI: 10 .7936/K7T43SN7.

U.S. Government Accountability Office. 2020. “Higher Education: Children's Savings Account Programs Can Help Families Build Savings and Envision College." GAO-21-10. Washington: Government Printing Office. Accessed December 22, 2020. https://www.gao.gov/products/gao -21-10.

Zager, Robert, Youngmi Kim, Yunju Nam, Margaret M. Clancy, and Michael Sherraden. 2010. “The SEED for Oklahoma Kids Experiment: Initial Account Opening and Savings." CSD research report 10-14. St. Louis, Mo.: Washington University, Center for Social Development. DOI: 10.7936 /K7Z31Z55.

Zucman, Gabriel. 2019. "Global Wealth Inequality." Annual Review of Economics 11:109-38. DOI: 10.1146/annurev-economics-080218-025852. 